\title{
TRUE LOVE SHINING THROUGH THE ECLIPSE OF CONFLATION: WOJTYLA'S NOTION OF LOVE AND THE MACHINATIONS OF TOLERANCE AND INCLUSION
}

\author{
Ferdinand D. Delos Reyes \\ University of Asia and the Pacific
}

\begin{abstract}
Tolerance and inclusion - the adamant mark of political correctness are among the notions that best characterize contemporary time. These ideas generally express themselves as attitudes that pave the way for processes to afford accommodation into discourses of what may even be evidently false so as not to offend those holding the opposite and minority views. Such an attitude of misplaced intellectual benevolence has tarnished many aspects of daily life: academic, corporate, social, political, and even theological.

Whereas the idea of love is involved, it can be lucidly observed how true love is going through tough times given the present state of affairs. There are good reasons to believe that Love is being defined anew in the name of tolerance and inclusion to include instances devoid of the ground upon which true love grows - the common good. Love, the most basic emotion, the attitude proper and perfective of the human person and best manifested in the pouring out of oneselffor the authentic good of the other must not be allowed to be eclipsed through oversimplification and be conflated with notions actually diametrically opposed to it, effecting depersonalization and human devolution. In light of the intensity of how political correctness asserts itself, allowing the ugly to be raised and seen as something beautiful, and that which has no sense to be understood as profound, Karol Wojtyla's (Pope John Paul II) compendium of ideas and timeless articulation on the notion of love is definitively potent to the cause of authentic human flourishing.
\end{abstract}

\section{INTRODUCTION}

This paper discloses its message in three portions, utilizing lucid language throughout; the first portion presents prevailing situations that essentially curtail and regulate speech. The subsequent analysis employing a functional knowledge and 
percipience of the critical theory leads to the unfolding of the underlying problem of conflation and its fruits as it affects the notion of love, manifested chiefly through a subtle but radical social and cultural imposition to practice tolerance and inclusion, albeit as it will show, in the context of critical theorists.

The second portion discusses Wojtyla's personalistic and phenomenological elucidation of the notion of love, its grounding on a valid notion of a common good, and the logical consequences that follow. The accuracy with which his explanations conform with reality brings to the fore a concern that translates to an inevitable imperative to put the phenomenological understanding of love at man's perfective disposal. The concluding portion involves, for my part, a reiteration of the feasibility of Wojtyla's notion of love as against the conflated notions that mimic love, accentuating its ameliorating potential towards a repossession of true love's eclipsed meaning.

\section{INDICATIONS OF THE PROBLEM AT HAND}

\section{A tough time for free speech and free expression}

There is a specter that has been imposing itself in the minds of people, particularly young men and women, with the primal effect of self-censorship but leads to the acceptance of redefinition of life-changing concepts. This phenomenon is most evident but not restricted to what has been happening in United States colleges and universities. It manifests itself through the control of thought by controlling speech through the existence of campus speech codes, safe spaces, and disinvitation of speakers. Nowhere should the human right to free speech be more valued than in colleges and universities, for, through it, the formation of a truly discerning mind becomes a possibility.

After all, higher education is not so much about insulating students to what may disturb their beliefs but rather giving them a simulation of reality, preparing them, intellectually and even morally inoculating them for the world after graduation by exposing them to true diversity (Gup 2011). This, in its essence, is a diversity of ideas from both left and right, not ethnic, not religious, etc.

As higher education has a societal role in shaping young minds, it is the unique task of colleges and universities to be the vanguard of free thought, expression, and speech. The rise in the adherence of educational institutions to the trend of affording safe spaces and a general drop in support of the human right to free speech by the academe as indicated by campus safe spaces and speech codes evidences a current trend of suppression of speech in favor of the notion of tolerance with its enabling principle of inclusion to result in the leftist notion of diversity.

The Foundation for Individual Rights in Education or FIRE (2009, 3-4; 2019, $1-2$; 2020) — an advocacy group defending and sustaining the individual rights of students and faculty members in the United States testifies to the stated indications through its arsenal of data on all the matters mentioned above. ${ }^{1}$

\section{An analysis of the indications}

To be prevented from speaking one's mind and call a thing by its name or the 
term designated to it is a sad event. It prevents the identity of a particular reality from being established and be dealt with accordingly by the mind utilizing the right reason. It inhibits and restricts the bringing about of what can and need be essentially said of that reality and learn from them. This first possibility precludes for man opportunities to inter-subjectively express and learn. A man's legitimate message being branded 'offensive to the thought and emotions of others or be labeled as hate speech' gets censored. Man's fundamental way of expressing his freedom, which is through free speech, gets bound and restricted, his opportunity to dialogue and lay his arguments versus opposing views get thwarted, the process of gaining fuller understanding becomes frustrating, and the existential growth for all parties concerned gets stunted.

There is a second possibility, suppose in the name of tolerance, we are allowed to utter or mention the term which represents a concept, only this time inclusion is carried out, something new is admitted into what constitutes the said concept. Although it can be said that in the study of linguistics, human language experiences change, a sort of evolution, or, perhaps even devolution, through the admission of aspects into what constitutes the concept, the main question will be whether the concept represented by the term remain the same or will it actually become something else only that the same term is used to pertain to it? In this situation, there can be several instances.

In the first instance of the second possibility, if what is admitted into what constitutes the definition of a thing is non-essential, the effect may be either a sort of qualifying/specifying or a widening of the term's extension or application. In the second instance, if what has been admitted constitutes a substantial or essential change of the concept, it may well be regarded as a different thing altogether only that the term that represents it remains the same. The second possibility may even subsume the first possibility. Man gets lost in falsehood, and the most evident truths predictably get reduced to the status of opinions.

In the second instance of the second possibility, deliberate or not, the case can be described as a reinvention of a concept to the effect of actually meaning a totally different thing but referred to using the same term. The second instance is an instance of a conflation I shall refer to throughout this paper. The conflation essentially happens in two ways, first, by admixing something new into the concept, or, second, by removing what is essential to it, thus changing the concept entirely, although named the same. This is problematic because it results in confusion, a confusion with far-reaching consequences like the setting off of thought patterns or false concepts that muddle the understanding of reality, misguiding whole societies, and even ensuing generations.

\section{On the rootedness of the conflated view of love}

One of those notions that are often confused and conflated is love. While free speech and free expression, and diversity of ideas about love is a welcome development, there is a need to articulate the true meaning of love. It is tempting for any child of the generation to accept as true things and situations to which one was born. It is thus highly probable for anyone new-in-the-world to have accepted instances of conflated ideas without questioning. Two such specimens that efficiently captures the narrative of the conflated idea of love are in the form of slogans. Slogans are short, well-crafted phrases encapsulating the belief or ideals that guide an individual, groups, 
and institution to be used either in any or all of the following simultaneously: public persuasion, advertising/generating awareness, and subtle indoctrination. What is pertained here are the slogans of "love is love" and "love wins." However, a word need be said prior to the articulation, note that 'Love' - the topic underlying the many claims to its various expression which are in question here has never been defined by those who make a claim to it. It is as if it is assumed that everybody knows what love is or that the understanding of what love means is the same for everyone.

As a slogan or even as a maxim, "love is love" - by its very succinctness is an oversimplification of what love truly is. The oversimplification, whether deliberate or not, removes, if not takes for granted two essential aspects of love or the act of loving, firstly, that love, human love that is, has or must have a proper object, ${ }^{3}$ secondly, a proper reason for the sake of which one loves at all.

The answer to the first concern determines whether the love involved is humanly licit ${ }^{4}$ to the parties involved. The answer to the second will show if the love afforded or offered is directed at the beloved and for the sake of that beloved, or still directed towards the beloved but for the sake of the initiating agent. The outcome of the second concern will determine if the act was that of love for the sake of the beloved or an act ultimately directed to serve the self. If the latter is the case, then what transpired has not involved love at all. Call it by another name/term but not love. And if a man claims to love and claims that his acts are really out of love when it is not, just how human does the man make of both of himself and the so-called object of his love?

Thus, in most if not all cases, these are instances of objectification or utilitarianism. Love was never actually given nor received for it was never understood, it was not understood, not because it cannot be understood but that the understanding of love was eclipsed by either admixing it with notions alien to it or, by watering down the meaning of love in such a covert fashion and degree so as to include or identify love with other ideas that only bear a fraction of its total aspects. Hence, the possibility of people failing to render love is so because people render some other thing mistakenly thought of as love but is not so. People render semblances of love other than true love because they do not even know what love truly consists in.

Hence, it becomes predictable to see how the rootedness of the conflation stems from the process of oversimplifying the meaning of things. In this case, the oversimplification of the definition and meaning of love eliminates from it all splendor and heroism except the intensity of the emotion that accompanies it. Because of this oversimplification of love, it is easy to identify love with other terms or concepts that only have emotional intensity at its core. This may well be the reason why people mistake lust, in its varying forms, i.e., fornication, cohabitation, adultery, same-sex marriage, child marriages, and even the odd relationships with animals or inanimate objects, for love.

One of the aspects, if not the vital aspect, which disappeared in the proper understanding of love because of an oversimplification but that actually and fundamentally distinguishes love from its semblances is the notion of the common good. Karol Wojtyla (1981, 28-29), or Pope John Paul II and later Saint John Paul II, articulated in Love and Responsibility that the only thing which may preclude a person from using another person is the notion of love as grounded on the common good. The common good is a valid good understood and aimed at by the parties involved in love. Such good 
enables them to unite them from within, knowingly and willfully subordinating themselves to this good which makes up their common end, and subordinating themselves to each other for the sake of this same good. Thus, this common good becomes the precondition or the ground upon which love, as the opposite of using, may grow and blossom. Somehow, to actualize a person's dormant power to love is deeply contingent on his readiness to pursue a common good with others, subjecting himself to it for the other person's sake and/or allowing himself to be subjected to the other person for the sake of the common good. The absence of a valid common good in any human relation for Wojtyla has the logical consequence of ending up practicing some form of using. As such, he saw the common good to be the formula able to generate the possibility to elude the exercise of any human action variant of the notion of utilitarianism.

\section{Associating the force behind the conflation}

If man so wills, whatever it is in his mind may get expressed with relative accuracy depending on his ability to make use of language. Language involves most basically, concepts. The term is the technical word that represents concepts or ideas. Men ordinarily use words orally or in a written fashion to express their thoughts. The more words and concepts a man know, the more efficient and possibly, the more artful his manner of expression will be via speech.

However, man also has another use for language. Man learns via language. Man learns by way of the words he encounters via study, reading, listening $\&$ dialogue. The more truthful and accurate a concept has been expressed, the more understanding the learner gets from it. Terms or words that represent a concept have a disclosive power that is supposed to fuel the lighting of the mind. But then a peripheral question arises, what if one's understanding of a concept is affected by its equivocality in semantics; in virtue of which, it can be further asked, what if the terms which represent concepts can be controlled to produce the equivocal character strong enough to effect conflation whether by adding or removing essential things in the terms' definition? If this situation is true, who would do such a thing, and for what motive? The think tank Institute for Social Research, or the Frankfurt School, is the force that accounts for the efforts to conflate key structural ideas upon which western civilization stands, employing their chief strategy of the Critical Theory commonly known as political correctness, which is much about systematically generating control of mindset, behavior, and action through deconstruction (Lind 2000, para 14-21).

Controlling who may speak and who may not speak is to control speech; controlling what one has to say is also to control speech. Control language and the contents of speech, which includes the terms of concepts, and the meaning and truths such terms carry become equivocal and vague. To control language via the control of the material content thereof can lead to the control of meaning, thus possibly reauthoring the grand narratives. Hence, controlling language by controlling the meaning of terms results in conflating them. The act achieves some sort and measure of control of concepts, truths, and thoughts. Control thoughts and one can have a considerable measure of control over how people will act or behave...changing culture (Lind 2000, para. 27). 


\section{Understanding how tolerance and inclusion work}

A few decades ago, people who belonged to the marginalized sections of society in the United States had been made to strongly feel and think they were and are being oppressed. It was followed by a grand and elaborate upheaval that had and continue to have for its goal the infiltration of discourses in many aspects of daily life: identity, sexuality, race, the academic (whether in literature, art, ethics, etc.), corporate, social, political and even theological, its deconstruction and the rewriting of truth, all leading to a change in culture suited for the emergence of the Marxist ideal (Lind 2000, para. 10). Evidence instrumental to the agitation of the marginalized sections, i.e., homosexuals, blacks, Latinos, Muslims, women, etc., are the combined works of Horkheimer, Fromm, Adorno, Neumann, Lowenthal, and Marcuse (Jay 1996, 41-85).

Tolerance and inclusion, as it is being used in college campuses, not just in the United States but the world over, are methods of cultural Marxist expropriation (Lind 2000, para. 9). Moreover, this is how political correctness works or is expropriated into mainstream society; its enforcement is carried out through a veiled practice of tolerance. This tolerance is unlike the tolerance an average person understands of the term. In the lingo of Marcuse (1965, 95-96) it is called 'Repressive Tolerance' - a sort of liberating tolerance denoting that only cultural Marxist liberating views are to be tolerated; opposing views consisting chiefly of traditional views are to be actively repressed. Non-compliance or resisting it or arguing against it results in one being labeled a bigot, a homophobe, an Islamophobe, a racist, a sexist, a xenophobe, a fascist, etc. Such was what transpired as Marxism was translated from economic into cultural terms. Thus, the leftist notion of tolerance can be described as an attitude that will allow entry into discourse, even the unreasonable views of those who call themselves oppressed and claim to belong to marginalized or victimized sections of society. Inclusion, on the other hand, would refer to the process of admitting entry to such views. One tolerates so as to include.

Tolerating and including/accommodating a conflated and false understanding of reality in order to achieve a vague sense of diversity can be nothing else but to embrace error willfully. The thing about error is this; the honest mind cannot tolerate it. Can the intellectually honest take in the proposition that a triangle and a square have no essential difference as polygons? However, sadly, it is precisely the case of truth that via the context and use of tolerance and inclusion, gender identity has become a staple issue, more so when backed-up by supposedly scholarly papers (Stossel and Lott 2019) arguing that no essential differences between male and female exist. The general description of the trend in many discourses is one of unabated questioning, the sort of which never seems a bit concerned for an answer but just persistently asserts that something is wrong with the subject at hand. What seems to matter is simply keeping questioning to the point of casting or effecting serious doubt into the understanding of reality so obvious to the intellectually honest and/or even making the intellectually honest doubt his own judgment or sanity. This trend is constitutive of the varying manifestations of political correctness, otherwise known as Critical theory (Lind 2000, para. 20-21). The case of love is the same. In the political preface of Herbert Marcuse's (1956, xv) book "Eros and Civilization," he indicated that a good society should be based on what he calls polymorphous sexuality — a term coined by Freud, indicating 
that by liberating man's non-procreative eros, mankind can achieve happiness. He gave people the ideology they wanted to justify doing what they always wanted. Hence, such people take free love and its species, i.e., fornication, cohabitation, adultery, same-sex relationships, etc., to mean love.

Whatever reason others may have to tolerate and include, it must be remembered by the intellectually honest that what is self-evident or obvious is central to any discussion concerning proof. Indeed, there is much to be realized in discerning what is evidently true using Aristotle's dictum: "more dependence must be placed on facts than on reasonings, which must agree with facts."

\section{WOJTYLA'S ARTICULATION OF LOVE}

The problem concerning the eclipse of love's true meaning is not necessarily a modern one; instead, the problem has been an enduring one throughout human history as man's nature is immutable. Although the world continues to have new people, these new people will have to deal with old, i.e., existential problems.

\section{To "Use"}

In Love and Responsibility, Wojtyla (1981, 21-34) accounts for human actions having claims to love as their foundation but are actually contrary to it; he did so by first probing into the most basic structure of human activities that give rise to the possible emergence of love. No man is an island; as the adage goes, man does not possess everything he needs to possess in order to improve, develop, grow, or mature. Inevitably, we shall need other people to learn from, who would provide for things we do not have as yet to become continuing better versions of ourselves or become closer to our desired goals in life. The need elicits the notion of "to use."

Wojtyla understood the verb "to use" is a decisive thought for man; it appears in the early part of the same book setting the foundation for a deeper understanding of what love is not. Conversely, it allows for the recognition of the value of the thing supposedly being used together with the underlying reason for one's action towards an object, especially when an object is a person, whether the act was done was for one's own sake or for the sake and good of another.

According to Wojtyla $(1981,25)$, the first meaning of 'to use' is to make another person a means to achieve one's particular end. The second meaning is to experience pleasure, that is, to enjoy. If subscribed to, the first meaning will lead to treating another person, or even of oneself - if one so desires, as an object to be used. The second meaning of 'to use' may result in, in virtue of man's power to reason, make him recognize and distinguish what is pleasurable from what is not, and, with the same power, man can detach pleasure and treat pleasure as a distinct aim of his actions.

Man is a person, and as such, he has an intellect and free will; having free will, he determines his goals and freely moves to achieve them. As man is free, he is his own master. He must be the one to ultimately will for himself. If he is to be true to his nature, he must be independent in his actions. To impede man's capacity to master himself by treating him as an object and to force one to will what one wants is a 
violation of that person's dignity. Moreover, whoever does so with other persons violates his own. In the course of human relationships, man can almost always have for his object other human beings who are also subjects. The scenario demands, by what rule must man conform himself so as not to intrude in another subject's incommunicability?

\section{Love and Affirmation of Person}

The rule is simple but packed with definitive power. The rule is love. Wojtyla understood that love is the opposite of utility - the very reason why man almost always treats others as objects. So now we must ask, what is love? Love is to see and to affirm the value of a person. However, how does this happen? How does one affirm the value of that which he does not yet know? How will one know if one is not in a variant of equal footing with others in a relationship? Thus, something very important must be noted, a sort of precondition if the affirmation of value is to happen at all, and that notion is the common good. Every man must arrive at a notion of a goal that he sees or understands as a good he freely takes for himself; this same goal must be seen and understood as a good by others and must be freely taken up as their own. This shared goal to which individuals freely submit themselves to results with the same individuals freely submitting themselves to each other for the sake of this shared goal or good, this good we call the common good. The common good is the ground upon which the seed of love is sown, because of which the possibility of treating others as objects is prevented. This common good can take many forms in human relationships. We have the common good for marriage, the common good of a nation or citizenry or institutions, etc. Even if it is conceivable that the common good is hard to attain to the point that individual goods need be sacrificed to allow for its emergence is no argument against it, but rather lucid evidence of its greatness and fullness (Aguas 2014, 183).

To love is to affirm the value of the person; to affirm is to act upon or posit that value appropriately. In the case of the love between a man and a woman, as love matures, the affirmation of the value results in making oneself the best gift possible and in the total giving of the self in marriage logically resulting (if all is well) in the begetting of new life (Wojtyla 1981, 95-100). This non-openness to new life shows how same-sex marriage runs counter to the proper order of things.

Peripherally, the context of the conflation articulated upon earlier includes the blurring of meaning. The importance and/or uniqueness of the notion of person is attacked by way of the denial of human nature, that men (who are persons) are only different from the brute by way of the degree of perfection he possesses but not essentially. This denial is not based on what is self-evident. Wojtyla referred to man's consciousness of his own uniqueness in a way that triggers common sense even as one does not have the gift of faith. In Wojtyla's work, Redemption of the Body and the Sacramentality of Marriage, more popularly known as Theology of the Body, Wojtyla (2006, 15-25) alluded to Adam as having experienced 'original solitude.' Adam, the first man, being a person, was conscious of his being different from the rest of the animated creation. Man may only have inter-subjectivity with fellow-subjects or fellow persons, not with animals or inanimate objects. Moreover, in the context of love, 'original unity,' the sort of properly oriented love the first man and woman had for each other cannot be 
duplicated by fornication, adultery, homosexual relationships, pedophilia, childmarriage, etc. Original unity reveals the proper object and context of sexuality.

A shining element that made Wojtyla's articulation of love between a man and a woman so distinct is the notion of responsibility. Wojtyla observed that innate in love is the sense of responsibility a lover has for his/her beloved; a beloved that has so completely entrusted, bestowed himself/herself so uniquely to his/her lover as a gift of self that the lover justly bears the sense of charge or duty as regards the most important aspects the beloved's authentic good. The excitement, the emotion, the enjoyment, and pleasure derived from being with one's beloved are secondary to the deep sense of concern a lover ought to have for his/her beloved's welfare, well-being, emotional security, happiness, and holiness. The value of the beloved, who is a person, always has the primacy over the value of whatever pleasure may be derived in virtue of the relationship. Wojtyla (1981, 130-131) said, "that the greater the feeling of responsibility, the more true, love there is." The same sense of responsibility sustains the lover to possess constancy in being of authentic service to the beloved. Such a sense of responsibility is absent in all forms of unions of egoisms that assert themselves as love.

\section{CONCLUSION}

In light of Wojtyla's ideas, the chief issues that claim love as their justification must be put to the test. As regards the maxim, "love is love," how can love be without the proper partner or be with any object? The case for human love is objectively structured to be grounded on a genuinely valid common good shared by those who subscribe to it. Human love, that is, the love between a man and a woman, is a 'valid relationship' that blossoms in the knowledge and love for each other, leading to marriage and the begetting of children.

If the partner in a relationship is of the same sex, the total self-donation of persons in virtue of love the spouses professes cannot manifest the ensuing logical consequence, which is to procreate or have children. More deviant is the case if the partner is a child or minor who lacks the basic knowledge and the maturity to enter into such a relationship. The most deviant is the case where the object of love is an animal or an inanimate object.

In a slightly different way, the maxim "love is love" likewise cannot be a justification for adultery, fornication, and cohabitation, for clearly no sign is exhibited that it will manifest a valid notion of the common good for the parties involved. The only thing common being the self-satisfaction that could be generated. As regards the saying "love wins," to win means in some strong sense to prevail. Is love a subject that acts to make the possibility of prevailing make sense? Love wins means love has prevailed, but the aphorism is an open-ended one, hence conveniently open to various meanings. Human love is experienced and expressed by the agent or the person and is not carried out by itself.

Love as the affirmation of the value of a person is the attitude apt towards a human person. As such, love is compatible with and perfective of man's nature. Love promotes and provides the condition for the authentic building of the self towards the maturity proper of a human being. Notions that mimic love claiming for itself the 
name but not grounded on a valid common good cannot be regarded as love at its core and only destroys the human person sooner or later.

Service is the very mark of love. As one serves, it does not necessarily mean one loves. However, as one loves, one cannot help but serve. As one loves, one serves the beloved; the service is directed at the perfection and happiness of the beloved, not at the self. As one serves, one gives whatever is worthy in his self for the benefit of the beloved and not himself. Upon the light of love is a civilization built. True love has been going through tough times; it has been experiencing prolonged eclipses, veiled by errors that can only emit semblances at best. Love is a virtue; its semblances are vices. Thus understood, Wojtyla's articulation opens a horizon of perfecting possibilities for the human person.

\section{NOTES}

1. I have chosen to use data from the United States as it embodies the expression of freedom via speech and other manners of expression.

2. "Love is love" and "love wins" are slogans that, although almost always seen in LGBTQ activities, may not reason- wise, be exclusively held as a guiding principle only by those who advocate that love knows no gender or sexuality. It can also be held implicitly by those who love or claim to love but for the wrong reasons and wrong circumstances, i.e., fornicators, adulterers, etc.

3. By proper object is meant a qualified mature person of the opposite sex able to reciprocate the love received. It is not a non-person.

4. By humanly licit, love is meant a love that is allowed and permissible as it is valid between the parties involved, i.e., the love between husband and wife, who are both mature persons of the opposite sex. Examples of an illicit love are the likes of pedophilia, extra-marital affairs, or love between the same sexes, particularly as the latter is anthropologically unsound as it cannot result in total self-giving, manifested by the fact that it will not result in procreation. Worst of all is the sick love appropriated by some men to animals or inanimate objects.

\section{REFERENCES}

Aguas, Jove Jim S. 2014. Person, action, and love: The philosophical thoughts of Karol Wojtyla (John Paul II). Manila: UST Publishing House.

Foundation for Individual Rights in Education. n.d. Disinvitation database. Thefire.org. https://www.thefire.org/research/disinvitation-

database/\#home/?view_2_page=18. Accessed: December 28, 2019.

Foundation for Individual Rights in Education. 2009. Spotlight on speech codes. Thefire.org. https://d28htnjz2elwuj.cloudfront.net/wpcontent/uploads/2016/05/17121617/Spotlight-on-Speech-Codes-2009.pdf.3-4.

Accessed: December 31, 2019.

Foundation for Individual Rights in Education. 2019. Spotlight on speech codes. Thefire.org. https://d28htnjz2elwuj.cloudfront.net/wp- 
content/uploads/2019/02/08150756/SCR_2019.pdf.1-2. Accessed: January 23, 2020.

Gup, Ted. 2011. True diversity includes both left and right. The chronicle of higher education. https://www.chronicle.com/article/true-diversity-includes-both-leftand-right/. Accessed: February 2, 2020.

Jay, Martin.1996. The dialectical imagination: A history of the Frankfurt School and the Institute of Social Research 1923-1950. Berkeley and Los Angeles: University of California Press.

Lind, William. 2000. The origins of political correctness. Accuracy in academia. https://www.academia.org/the-origins-of-political-correctness/. Accessed: January 5, 2020.

Marcuse, Herbert. 1956. Political preface. Eros and civilization: A philosophical inquiry into Freud. England: Routledge, Kegan Paul, Ltd.

Marcuse, Herbert. 1965. Repressive tolerance. A critique of pure tolerance. Boston: Beacon Press.

Stossel, John and Maxim Lott. 2019. Academic hoax. Reason: Free Minds and Free Markets. https://reason.com/2019/03/05/stossel-academic-hoaxes/ Accessed February 17, 2020.

Wojtyla, K. 1981. Love and responsibility. Translated by H.T. Willets. California: Ignatius Press. (Original work published 1960).

Wojtyla, K./John Paul II. 2006. Redemption of the body and the sacramentality of marriage. Vatican City: The Catholic Primer-Electronic https://d2y1pz2y630308.cloudfront.net/2232/documents/2016/9/theology_of_the _body.pdf., 15-25. Accessed: November 5, 2019. 